\title{
Self-Esteem of Imprisoned Female Addicts: Is it Important to Community Health?
}

\author{
Mahya Torkman ${ }^{1}$; Sakineh Miri ${ }^{2, *} ;$ Jamileh Farokhzadian ${ }^{3}$ \\ ${ }^{1}$ MSc student of nursing, School of Nursing and Midwifery, Kerman University of Medical Sciences, Kerman, Iran. Tel: +9136500378, E-mail:Mahya.torkman@yahoo.com \\ ${ }^{2}$ Department of Nursing Research Center, Kerman University of Medical Sciences, Kerman, Iran \\ ${ }^{3}$ Department of Community Health, School of Nursing and Midwifery, Nursing Research Center, Kerman University of Medical Sciences, Kerman, Iran \\ ${ }^{*}$ Corresponding author: Sakineh Miri, Kerman University of Medical Sciences, Haft-bagh Highway, Kerman, Iran. Tel: +9131404498, fax: +98-3431325218, E-mail: miri.education@gmail. \\ com
}

Received: 22 Sep 2016

Accepted: 21 Nov 2016

Ppub: 23 Dec 2016

\begin{abstract}
Background: Drug use causes inappropriate behaviors in women that are quite different from those in men. Social deviations, prostitution, high-risk sexual behaviors, abortion, divorce, imprisonment, followed by loss of self-esteem are consequences of women's addiction. Self-esteem is a basic human need that is present in all aspects of life, even in stressful situations. Self-esteem is the degree of self-approval and self-worth an individual regards for himself/herself. Thus, the present study aimed to investigate self-esteem of imprisoned female addicts.

Methods: The present study recruited 130 imprisoned female addicts in a prison in southeast Iran. Data were collected using demographic and Rosenberg's self-esteem questionnaires.

Results: The results obtained showed that mean overall self-esteem was poor in these women (10.23 \pm 4.32 ), and $84.6 \%$ of them had low self-esteem, and none had high self-esteem. Women's self-esteem was significantly different according to the duration of their imprisonment $(\mathrm{P} \leq 0.05)$. No significant difference was observed in women's self-esteem in terms of place of residence, occupation, education, marital status, frequency of marriage, age, prison history, number of children, husband's job, pregnancy status, physical illness in the last month, psychological illness in the last month, history of drug use in the past year, or type of drug used ( $P>0.05)$. Conclusions: Low self-esteem score may be due to women's psychological problems, and their feeling of failure and humiliation in life. Furthermore, women have a more fragile morale than men. Their illegal behaviors, probably due to financial and domestic problems, leads to loss of self-esteem in them. Thus, educational programs for improving women's psychological characteristics and boosting their self-esteem, especially in female prisoners are essential. It is recommended that further studies find the reasons for women's high-risk behaviors and strategies to reduce them, so as to improve family and community health.

Keywords: Self-Concepts; Prison; Women; Addiction
\end{abstract}

